Application of Neutron-Absorbing Structural-Amorphous Metal (SAM) Coatings for Spent Nuclear Fuel (SNF) Container to Enhance Criticality Safety Controls

J. Choi, C. Lee, D. Day, M. Wall, C. Saw, W. MoberlyChan, J. Farmer, M. Boussoufl, B. Liu, H. Egbert, D. Branagan, A. D'Amato

November 15, 2006

2006 MRS Fall Meeting Boston, MA, United States November 27, 2006 through December 1, 2006 
This document was prepared as an account of work sponsored by an agency of the United States Government. Neither the United States Government nor the University of California nor any of their employees, makes any warranty, express or implied, or assumes any legal liability or responsibility for the accuracy, completeness, or usefulness of any information, apparatus, product, or process disclosed, or represents that its use would not infringe privately owned rights. Reference herein to any specific commercial product, process, or service by trade name, trademark, manufacturer, or otherwise, does not necessarily constitute or imply its endorsement, recommendation, or favoring by the United States Government or the University of California. The views and opinions of authors expressed herein do not necessarily state or reflect those of the United States Government or the University of California, and shall not be used for advertising or product endorsement purposes. 


\title{
Application of Neutron-Absorbing Structural-Amorphous Metal (SAM) Coatings for Spent Nuclear Fuel (SNF) Container to Enhance Criticality Safety Controls
}

\author{
Investigator: Jor-Shan Choi ${ }^{1}$, Chuck Lee ${ }^{1}$, Dan Day ${ }^{1}$, Mark Wall ${ }^{1}$, Cheng Saw ${ }^{1}$, \\ W. MoberlyChan ${ }^{1}$, J. Farmer ${ }^{1}$, Moe Boussoufi ${ }^{2}$, Ben Liu ${ }^{2}$, Hal Egbert ${ }^{2}$, Dan \\ Branagan $^{3}$, Andy D'Amato ${ }^{4}$ \\ Institution: 1. Lawrence Livermore National Laboratory (LLNL) \\ 2. McClellan Nuclear Radiation Center (MNRC) \\ 3. The Nanosteel Corp. (TNC) \\ 4. Plasma Technology, Inc. (PTI)
}

\section{INTRODUCTION}

Spent nuclear fuel contains fissionable materials $\left({ }^{235} \mathrm{U},{ }^{239} \mathrm{Pu},{ }^{241} \mathrm{Pu}\right.$, etc.). Neutron multiplication and the potential for criticality are enhanced by the presence of a moderator during cask loading in water, water incursion in accidents conditions during spent fuel storage or transport. To prevent nuclear criticality in spent fuel storage, transportation, and during disposal, neutronabsorbing materials (or neutron poisons, such as borated stainless steel, Boral ${ }^{\mathrm{TM}}$, Metamic $^{\mathrm{TM}}$, Ni-Gd, and others) would have to be applied.

The success in demonstrating that the High-Performance Corrosion-Resistant material (HPCRM) ${ }^{1}$ can be thermally applied as coating onto base metal to provide for corrosion resistance for many naval applications raises the interest in applying the HPCRM to USDOE/OCRWM spent fuel management program. The fact that the HPCRM relies on the high content of boron to make the material amorphous - an essential property for corrosion resistance - and that the boron has to be homogenously distributed in the HPCRM qualify the material to be a neutron poison.

\section{Applications to Spent Fuel Support Baskets}

Spent fuel destined for geologic disposal would be first loaded into a disposal container, typically holding twenty-one assemblies of spent Pressurized Water Reactor (PWR) fuel, or about 40 spent Boiling Water Reactor (BWR) fuel assemblies. A baseline spent fuel disposal container designed to hold 21 spent PWR fuel assemblies is shown in Figure 1. The outer-shell of the container is made out of a special Nickel-containing alloy C-22 (UNS \# N06022) for purpose of corrosion resistance. The baseline-design internal spent fuel storage support 
basket is made out of $\mathrm{Ni}-\mathrm{Gd}$ composite (shown in Figure 2), with nickel providing for corrosion resistance and gadolinium acting as neutron poison.

Figure 1 A Baseline Design Spent Fuel Disposal Container

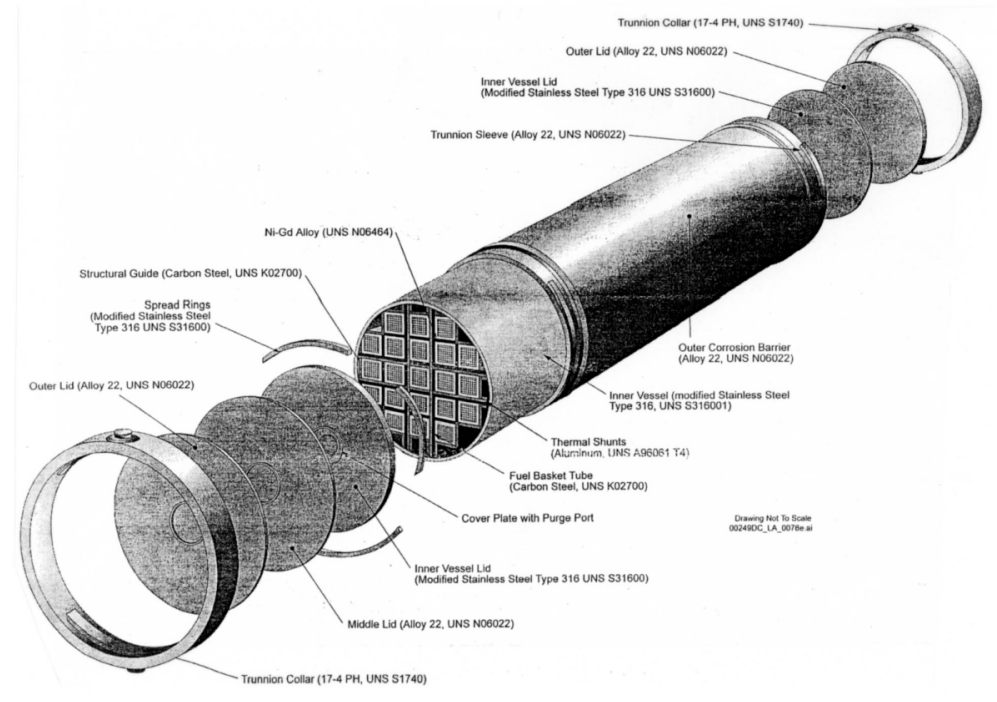

Figure 2 Baseline Design Internal Spent Fuel Storage Support Basket

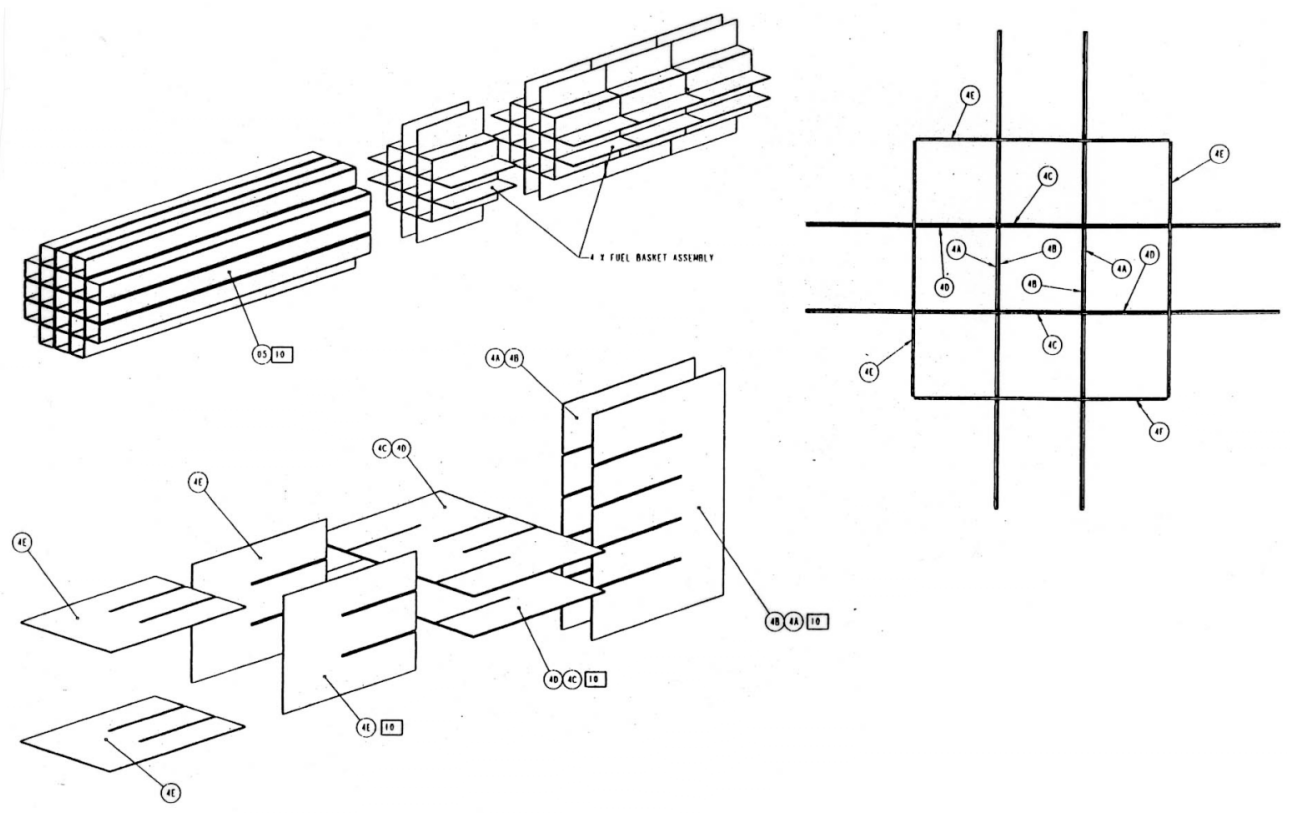




\section{USE OF HPCRM AS NEUTRON POISON}

Corrosion-resistant, iron-based amorphous metals have been tested to determine their relative corrosion resistance. Many of these materials can be applied as coatings with advanced thermal spray technology. SAM2X 5 is an amorphous-metal alloy composition that has been identified as having outstanding corrosion resistance. Because of the high boron content, SAM2X5 can be applied as the neutron-absorbing coatings to the metallic support structure to enhance criticality safety for spent nuclear fuel in baskets inside the storage containers, the transportation cask, and eventually the disposal container for repository disposal. Table 1 shows the atomic $\%$ and weight $\%$ of boron and carbon for both SAM2X5.

Table 1 Atom $\%$ and $\mathrm{Wt} \%$ of boron and carbon in SAM2X5

\begin{tabular}{|l|c|c|}
\hline SAM2X5 & B & C \\
\hline at \% & 15.2 & 3.8 \\
\hline wt \% & 3.22 & 0.83 \\
\hline
\end{tabular}

\section{SAM2X5 Coating by Thermal Spray}

To demonstrate the spray coating of the SAM $2 \times 5$ powders onto a metallic substrate, two $1 / 2$ scale stainless steel $316 \mathrm{~L}$ basket modules were fabricated. These two modules were of a similar baseline design made for storing 5 PWR fuel assemblies, and sized to fit a $1 / 2$ scale 30 "-diameter stainless steel container. Figure 3 shows the pictures of the pre-coated $1 / 2$-scale basket module put together in an assembly, the cutting of the slits by water jet to minimize the residual stress of the SS316L plates, and the $1 / 2$-scale containers which one of these containers can accommodate the 2 basket modules.

The SAM $2 \times 5$ powder and the pre-coated basket module plates are sent to Plasma Technology Incorporated (PTI) located in Torrance, CA for thermal-spray by the high velocity oxy-fuel (HVOF) coating method. The HVOF uses oxygen and a fuel gas as combustion media to accelerate the melted powder to high velocities through special designed nozzle and torch gun. This coating method has become the quality standard for carbide and cermets materials as gas velocities over 6,000 feet per second can be achieved to allow particle velocities over 3,000 feet per second. The result is a thermal-sprayed coating approaching theoretical density (e.g., very low porosity in the coating) with bond strengths at the coating-substrate interface about 10,000 psi. For the basket module, about $1 / 2$ $\mathrm{mm}$ of SAM $2 \times 5$ coating is applied to both sides of the stainless steel $316 \mathrm{~L}$ plates, achieving bond strengths approximately 8,000 psi. Figure 4 shows the coated basket module put together in an assembly. 
Figure $31 / 2$-scale basket assembly module, water-jet cutting of slits, and $1 / 2$ scale stainless steel $316 \mathrm{~L}$ containers
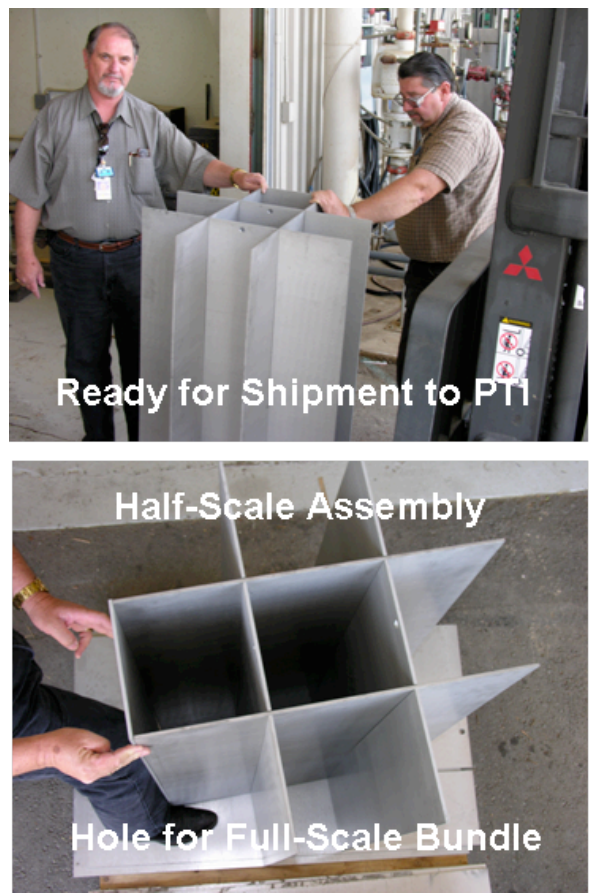

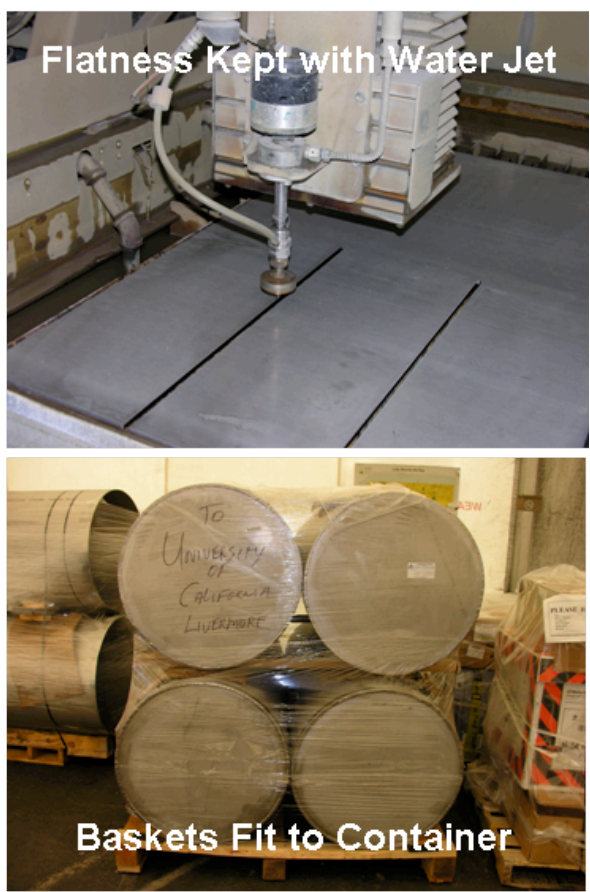

Figure 4 Inspecting the basket module coated with SAM2X5 by Plasma Technology, Inc. (PTI). The SAM2X5 powder s were produced by The Nanosteel Co. (TNC). (The picture shows from left: A. D'Amato of PTI, J. Buffa of TNC, C. Lee and J. Choi of LLNL)

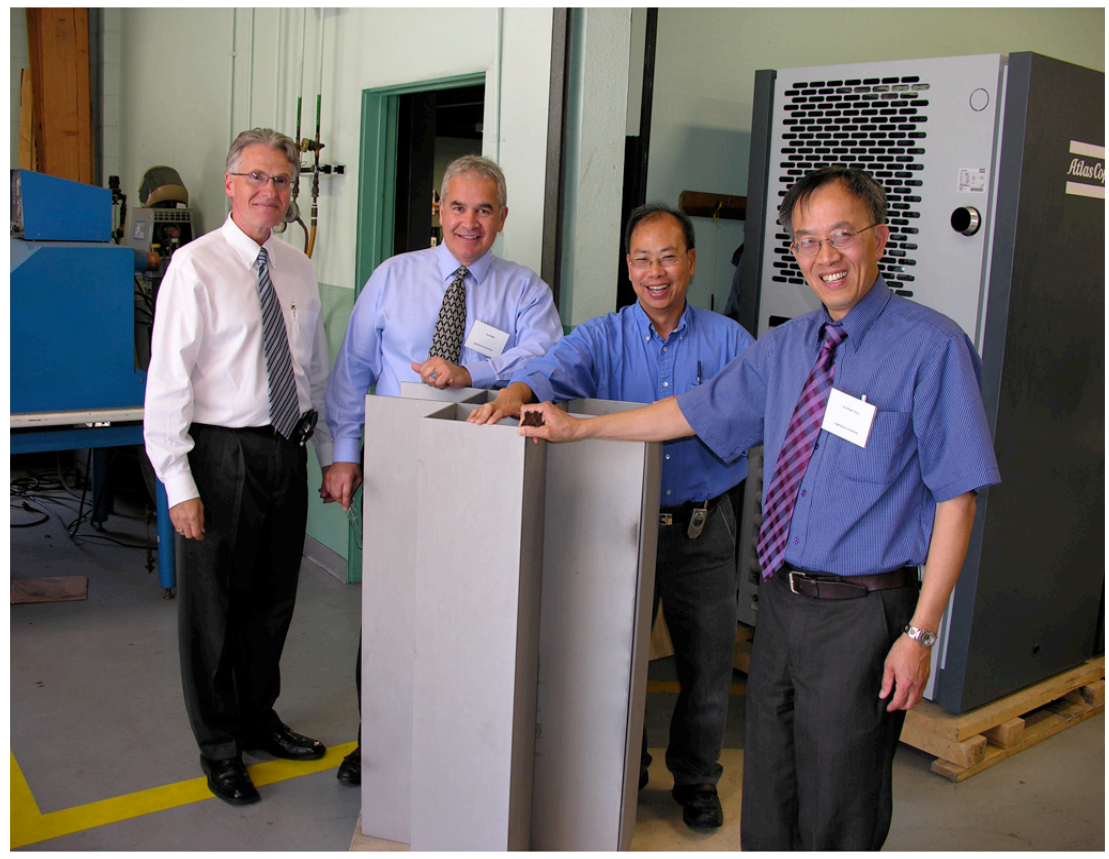




\section{CRITICALITY ANALYSIS}

\section{Criticality Evaluation for a Spent Nuclear Fuel Disposal Container}

A criticality evaluation of a disposal container designed to hold twenty-one spent PWR fuel assemblies is described in this Section. In the evaluation, each of the 21 Westinghouse designed $17 \times 17$ assembly contains 264 pins of spent $\mathrm{UO}_{2}$ fuel, and void spaces previously occupied by 24 guide thimbles and 1 instrumentation tube. Each fuel assembly at its beginning of life contains $423.2 \mathrm{~kg}$ of uranium, with $4.5 \mathrm{wt} \%{ }_{-}{ }^{235} \mathrm{U}$. The PWR fuel assembly is modeled at $35 \mathrm{GWd}$ /tonne of burn-up and with 10 year decay. Several fission product isotopes (e.g., ${ }^{149} \mathrm{Sm}$, ${ }^{103} \mathrm{Rh},{ }^{143} \mathrm{Nd}$, ${ }^{155} \mathrm{Gd}$, and ${ }^{83} \mathrm{Kr}$, etc.) are also included in the evaluation model. The presence of these fission product isotopes simulates a credit for burn-up of 35 $\mathrm{GWd}$ /tonne. The inclusion of these isotopes demonstrates the capability and flexibility of the evaluation model, and hence, the results are not intended for purpose of licensing application.

\section{Criticality Evaluation Model}

The evaluation model used in this analysis consists of PWR assemblies surrounded by $0.635 \mathrm{~cm}(1 / 4$ ") thick borated stainless steel of various concentrations of ${ }^{10} \mathrm{~B}$. A $1.27 \mathrm{~cm}(1 / 2 ")$ gap between the assembly and the borated stainless steel is allowed for packaging purposes. 21 assemblies are positioned in the disposal container, which has a diameter of $148 \mathrm{~cm}$ (58") ID. Each assembly is $25.227 \mathrm{~cm}$ (9.93") square. The model assumes a continuous fuel region instead of distinct fuel pellets for a simpler geometry configuration. Figures 5 and 6 show the configurations of a spent PWR fuel assembly and the internal of the disposal container holding 21 spent PWR fuel assemblies, respectively.

Figure 5 A $17 \times 17$ Spent PWR Fuel Assembly

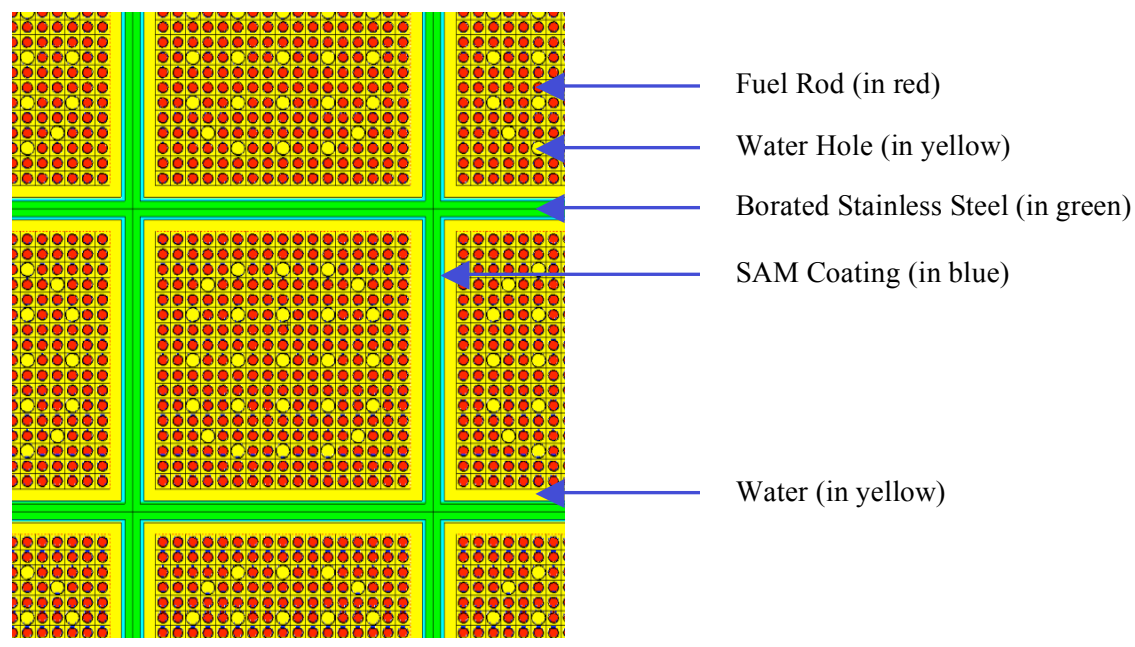


Figure 6 A Disposal Container Holding 21 Spent PWR Fuel Assemblies

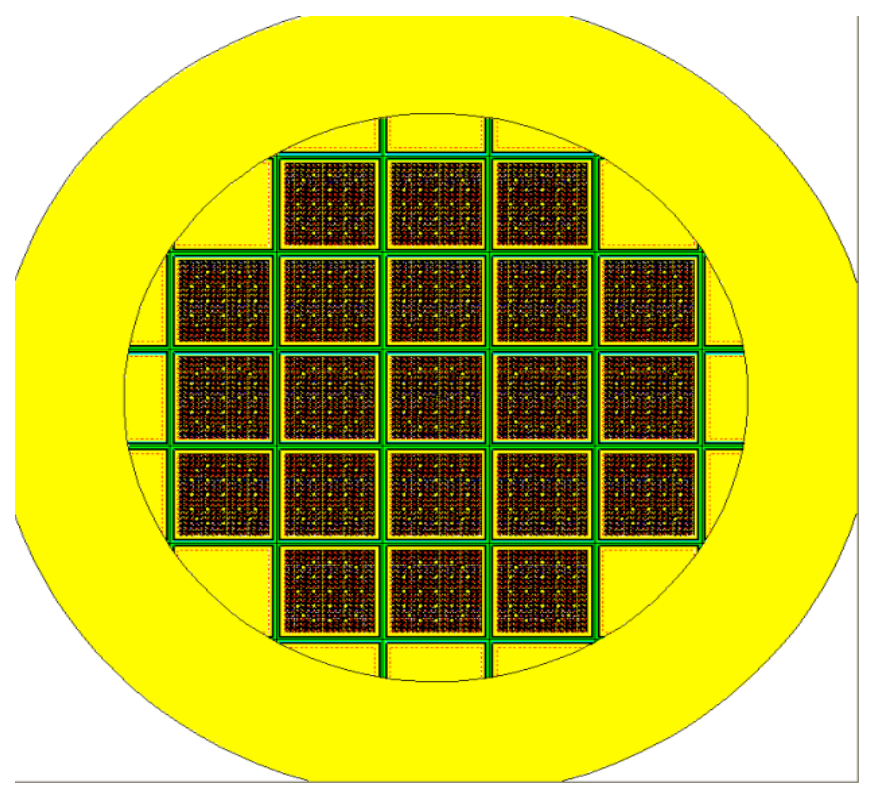

MCNP Version $5^{2}$ is a 3 Dimensional (3-D) Monte-Carlo transport code with continuous energy groups of neutron cross-sections. It is a state-of-the-art code, especially for design of complex geometry systems. The continuous energy Monte Carlo code MCNP5 can be used for modeling neutron transport in critical or sub-critical rectors. Multiplication eigenvalue $\left(k_{\text {eff }}\right)$ calculations can be made in order to find critical configurations, while in sub-critical systems, source neutron multiplication is explicitly modeled.

\section{Analysis Results}

Criticality evaluations are performed for a disposal container designed to hold twenty-one spent PWR fuel assemblies as described in Section 5.1. The computational model as shown in Figures 5 and 6 simulate each fuel pin within the $17 \times 17$ assembly. Each of the 21 assemblies is surrounded with $0.635 \mathrm{~cm}$ (1/4") thick borated stainless steel of various concentration of natural boron. A 1$\mathrm{mm}$ thick boron-containing SAM coatings are uniformly applied on the surface of the borated stainless steel, and hence, complementing the neutron-absorbing effectiveness of the borated stainless steel and reducing the overall $k_{\text {eff }}$ of the disposal container. The spent PWR fuel assemblies are exposed to a burn-up of $35 \mathrm{GWd} /$ tonne with a 10-year decay. Results of the criticality evaluations are obtained based on this computational model. 


\section{Borated Stainless Steel Basket}

The first set of calculations consists of borated stainless steel basket with various concentration of natural boron. Table 2 shows the evaluation results for 4 concentrations of natural boron and its neutron-absorbing isotope ${ }^{10} \mathrm{~B}$ which is about $20 \mathrm{wt} \%$ of the natural boron. The results in Table 8 indicate that with no boron in the system, the disposal container with 21 fuel assemblies would be above critical. The borated stainless steel basket with $0.12 \mathrm{wt} \%$ of boron would drop the $k_{\text {eff }}$ to about $4 \%$ of that of the no boron case. This amount of $\square k_{\text {eff }}$ is large enough to compensate for the computational bias ( $\square \mathrm{k}_{\text {eff }}$ of $0.29 \%$ ).

Table $2 \mathbf{k}_{\text {eff }}$ of Borated Stainless Steel Basket

\begin{tabular}{|c|c|c|c|}
\hline $\begin{array}{c}\mathbf{B}(\text { natural) } \\
\text { Concentration } \\
(\mathbf{w t} \%)\end{array}$ & $\begin{array}{c}{ }^{10} \mathrm{~B} \\
\text { Concentration } \\
(\mathbf{w t} \%)\end{array}$ & $\mathbf{k}_{\text {eff }}$ & $\square \mathbf{k}_{\text {eff }}{ }^{*}$ \\
\hline 0.0 & 0.0 & 1.008 & 0 \\
\hline 0.12 & 0.024 & 0.967 & 0.041 \\
\hline 1.0 & 0.199 & 0.904 & 0.104 \\
\hline 2.0 & 0.398 & 0.883 & 0.125 \\
\hline
\end{tabular}

${ }^{*} \square \mathrm{k}_{\text {eff }}$ is the difference in $\mathrm{k}_{\text {eff }}$ between the no boron case and borated stainless steel case

\section{Basket with SAM Coatings}

The second set of calculations consists of stainless steel basket coated with $1 \mathrm{~mm}$ of SAM2X5 and another SAM material SAM1651 (containing $1.24 \mathrm{wt} \%$ natural boron). The stainless steel basket contains either no or $0.12 \mathrm{wt} \%$ boron. The results are shown in Table 9 which indicates that the $1 \mathrm{~mm}$ SAM2X 5 is a more effective neutron poison than the borated stainless steel with $0.12 \mathrm{wt} \%$ boron, as the $\square \mathrm{k}_{\text {eff }}$ of $8.6 \%$ obtained with the SAM2X5 is 2 times higher than that of the borated steel case. A contributing factor would be the high boron content (3.22 wt\%) in SAM2X5. As SAM1651 has less boron (1.24 wt\%), it is not as effective a neutron poison as SAM $2 X 5$, but its neutron-absorbing effectiveness is comparable to the borated stainless steel.

The results in Table 3 also indicates that coating the spent fuel basket materials (e.g., borated stainless steel, Boraflex ${ }^{\mathrm{TM}}$, Boral ${ }^{\mathrm{TM}}$, Metamic ${ }^{\mathrm{TM}}, \mathrm{Ni}-\mathrm{Gd}^{\mathrm{TM}}$, etc.) with the boron-containing structural amorphous metal (SAM) would enhance criticality safety of spent fuel in wet storage pools, in dry storage containers, and in transportation casks. This high-performance corrosion-resistant SAM could also prevent the preferential leaching of boron from basket materials, and as a result, could improve the long-term criticality safety for waste package in repository 
Table $3 \mathbf{k}_{\text {eff }}$ of Stainless Steel Basket with SAM Coatings

\begin{tabular}{|c|c|c|c|}
\hline $\begin{array}{c}\text { SAM } \\
\text { Coating } \\
\mathbf{1} \mathbf{~ m m}\end{array}$ & $\begin{array}{c}\mathbf{B} \text { (natural) } \\
\text { Conc. (wt\%) } \\
\text { in borated } \\
\text { ss }\end{array}$ & $\mathbf{k}_{\text {eff }}$ & $\square \mathbf{k}_{\text {eff }}{ }^{*}$ \\
\hline SAM2X5 & 0.0 & 0.922 & 0.086 \\
\hline SAM2X5 & 0.12 & 0.915 & 0.093 \\
\hline SAM1651 & 0.0 & 0.951 & 0.057 \\
\hline SAM1651 & 0.12 & 0.938 & 0.070 \\
\hline
\end{tabular}

${ }^{*} \square \mathrm{k}_{\text {eff }}$ is the difference in $\mathrm{k}_{\text {eff }}$ between the no boron case and borated stainless steel case

\section{$\underline{\text { Ni-Gd Basket }}$}

For comparison, a case with the Yucca Mountain baseline basket material, Ni-Gd is analyzed. The Ni-Gd basket $(0.635 \mathrm{~cm}$ thick) contains $2 \mathrm{wt} \%$ gadolinium. Gadolinium is a more effective neutron absorber than boron for very thermalized neutron (i.e., neutron energy $<0.025 \mathrm{eV}$ ). While gadolinium isotopes $\left({ }^{157} \mathrm{Gd}\right.$ and ${ }^{155} \mathrm{Gd}$ ) have orders of magnitudes higher absorption cross sections and hence, are better neutron absorbers than ${ }^{10} \mathrm{~B}$ in the thermal neutron energy ranges $(<0.1$ $\mathrm{eV}$ ), their absorption capability dropped of very rapidly with higher neutron energy (starting from $\mathrm{E}>0.1 \mathrm{eV}$ ). The gadolinium cross sections also have a wide resonance region where the prediction of absorption capability varies widely. Contrastingly, ${ }^{10} \mathrm{~B}$ is a $1 / \mathrm{v}$ neutron absorber with known and predictable absorption cross section. It has been a preferred choice of neutron poison used by the industrial vendors. The calculation results for the Ni-Gd basket, as shown in Table 4 indicates that the effectiveness o Ni-Gd as a neutron poison is somewhat in between of the $1 \mathrm{~mm}$ thick SAM2X5 and SAM1651.

Table $4 \mathbf{k}_{\text {eff }}$ of Ni-Gd Basket

\begin{tabular}{|c|c|c|}
\hline $\begin{array}{c}\mathbf{G d} \\
\text { Concentration } \\
\text { (wt\%) }\end{array}$ & $\mathbf{k}_{\text {eff }}$ & $\square \mathbf{k}_{\text {eff }}{ }^{*}$ \\
\hline 2.0 & 0.926 & 0.082 \\
\hline \multicolumn{2}{|c|}{. } \\
${ }^{*} \square k_{\text {eff }}$ is the difference in $\mathrm{k}_{\text {eff }}$ between the no boron case and Ni-Gd case
\end{tabular}

\section{$\underline{1 / 2-S c a l e ~ B a s k e t ~ w i t h ~ S A M 2 X 5 ~ C o a t i n g ~}$}

The $1 / 2$-scale basket module with SAM $2 X 5$ coating was modeled and analyzed by using MCNP5. The model and the results are shown in Figure 7. The model indicates that only 5 PWR spent fuel assemblies can be fitted into the $1 / 2$-scale basket module, and the result indicates that there is a reduction of $12 \%$ in keff when the 1/2-scale basket is applied with $1 \mathrm{~mm}$ SAM2X5 coating. 
Figure $7 \quad 1 / 2$-Scale Basket Module and Criticality Evaluation Results

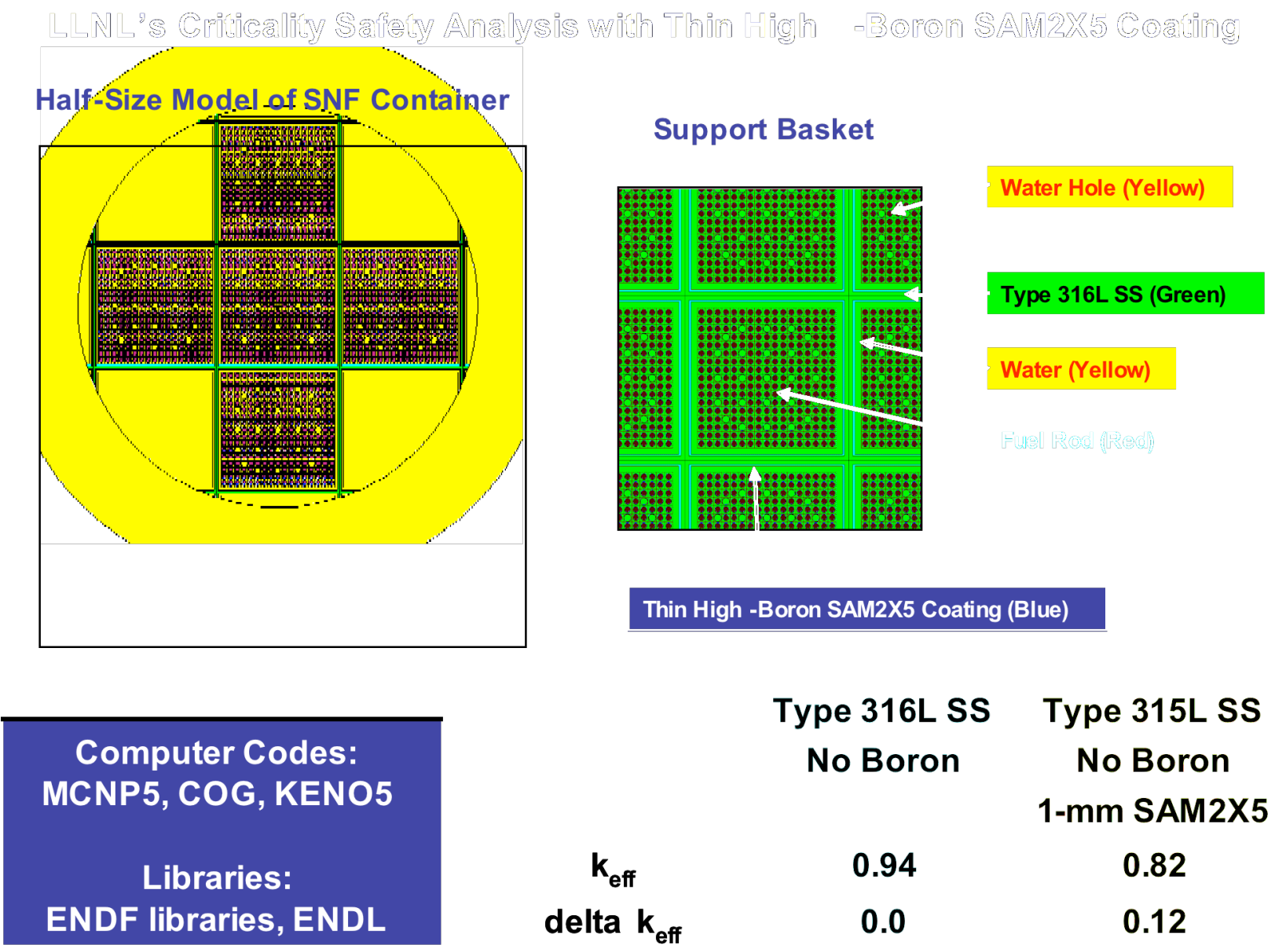

\subsection{NEUTRON EFFECT MODELING}

\section{Neutron Irradiation Facility}

The McClellan Nuclear Radiation Center (MNRC), operated by the University of California at Davis (UCD), is a facility operating a 2 Megawatt TRIGA reactor. The reactor produces $2 \mathrm{MW}$ of steady state power and 1,000 MW pulse power with thermal flux up to $3 \times 10^{16} \mathrm{n} / \mathrm{cm}^{2} / \mathrm{sec}$. The thermal and fast fluxes at the Central Core Facility (space of 4" dia. x 15" long) are up to $4.5 \times 10^{13}$ and $8.4 \times$ $10^{12} \mathrm{n} /-\mathrm{cm}^{2} / \mathrm{sec}$, respectively. There are several Out-Of Core Experiment Facilities within the reactor, including a Neutron Irradiation Facility (NIF) with a space of 7" dia. x 9" long. Figure 8 shows the reactor core internal and Figure 9 shows the outer container going into the NIF. 
Figure 8 MNRC Reactor Internal

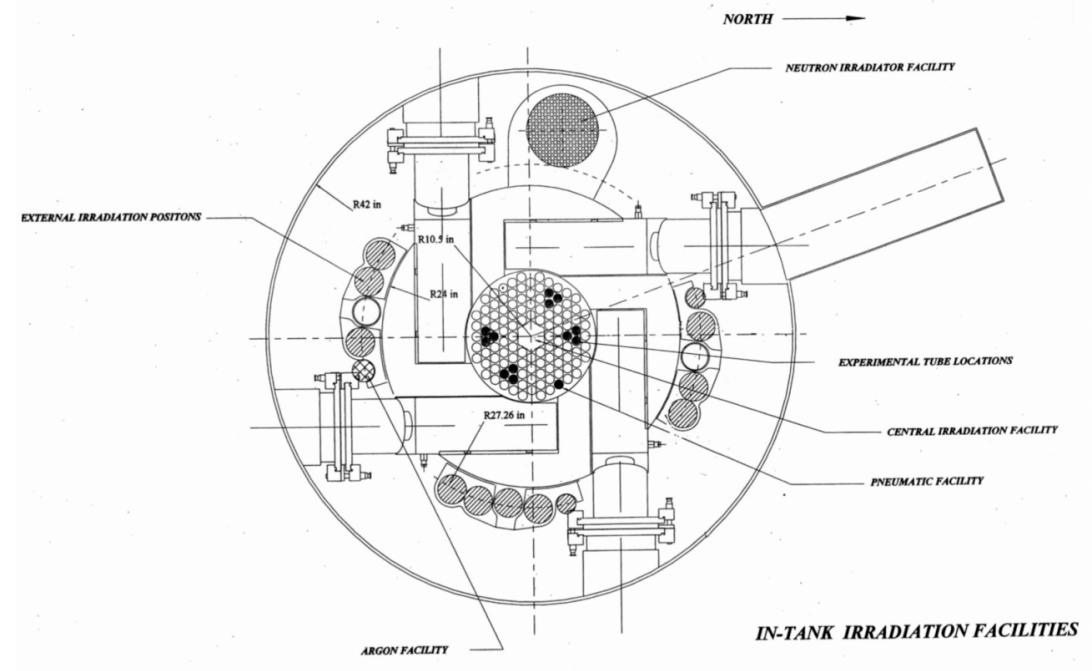

Figure 9 Outer Container for the Neutron Irradiation Facility (NIF)

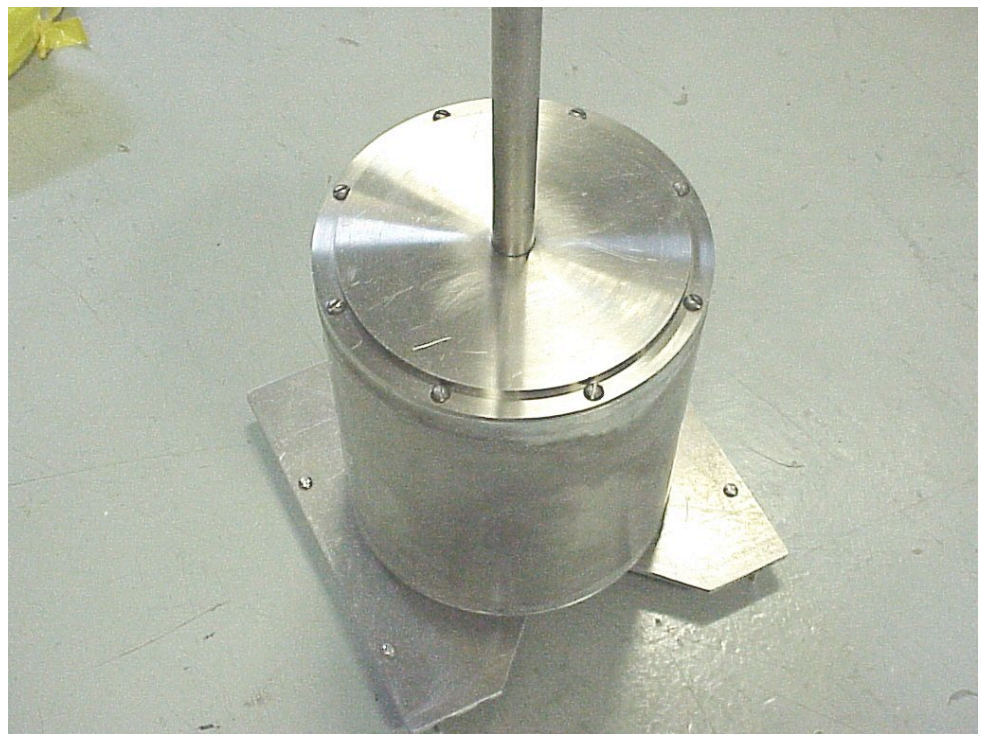

\section{Irradiation Experiment with Melt-Spun Ribbons}

Four series of SAM melt-spun ribbons are prepared for irradiation experiment in the NIF at MNRC. Table 5 shows the specific ingredients differentiating these 4 series of ribbons. Strips of these ribbons, about 4" long were cut and taped to a aluminum 
plates which were mounted onto the irradiator, to be inserted into the NIF for irradiation experiment. Figure 10 shows the strips of the 4 series of ribbons.

Table 5 Four Series of SAM Melt-Spun Ribbons Prepared for Irradiation Experiment

\begin{tabular}{|c|c|c|c|c|}
\hline $\begin{array}{l}\text { Ni Series } \\
\text { DAR40 + Ni) }\end{array}$ & $\begin{array}{l}+1 \% \mathrm{Ni} \\
\text { (SAM1X1) }\end{array}$ & \begin{tabular}{|l}
$+3 \% \mathrm{Ni}$ \\
(SAM1X3) \\
\end{tabular} & $\begin{array}{l}+5 \% \mathrm{Ni} \\
\text { (SAM1X5) } \\
\end{array}$ & \begin{tabular}{|l}
$+7 \% \mathrm{Ni}$ \\
(SAM1X7) \\
\end{tabular} \\
\hline $\begin{array}{l}\text { Mo Series } \\
\text { DAR40 + Mo) }\end{array}$ & $\begin{array}{l}+1 \% \text { Mo } \\
\text { (SAM2X1) }\end{array}$ & $\begin{array}{l}+3 \% \text { Mo } \\
\text { (SAM2X3) }\end{array}$ & $\begin{array}{l}+5 \% \text { Mo } \\
(\text { SAM2X5) }\end{array}$ & $\begin{array}{l}+7 \% \text { Mo } \\
\text { (SAM2X7) } \\
\end{array}$ \\
\hline $\begin{array}{l}\text { Y Series } \\
\text { DAR40 + Mo) }\end{array}$ & $\begin{array}{l}+1 \% \mathrm{Y} \\
(\mathrm{SAM} 3 \mathrm{X} 1)\end{array}$ & $\begin{array}{l}+3 \% \mathrm{Y} \\
(\mathrm{SAM} 3 \mathrm{X} 3)\end{array}$ & $\begin{array}{l}+5 \% \text { Y } \\
(\text { SAM3X5) }\end{array}$ & $\begin{array}{l}+7 \% \mathrm{Y} \\
(\mathrm{SAM} 3 \mathrm{X} 7)\end{array}$ \\
\hline$\overline{D A R}$ & $\begin{array}{l}\text { DAR7 } \\
\text { (SAM7) }\end{array}$ & $\begin{array}{l}\text { DAR8 } \\
\text { (SAM8) }\end{array}$ & $\begin{array}{l}\text { DAR9 } \\
\text { (SAM9) }\end{array}$ & $\begin{array}{l}\text { DAR10 } \\
\text { (SAM10) }\end{array}$ \\
\hline
\end{tabular}

Figure 10 Four Series of Melt-Spun Ribbons Taped on Aluminum Plates

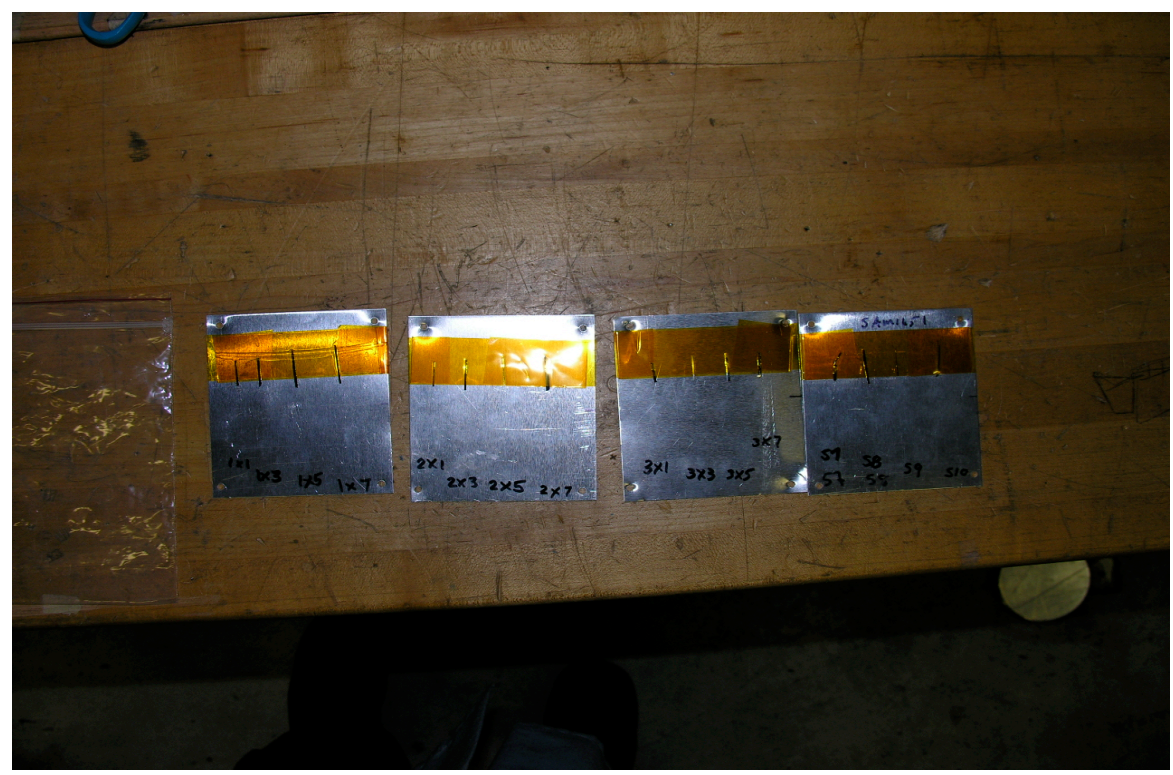

The melt-spun ribbons, after the XRD were taken are inserted into the NIF for a series of 3 irradiation cycles. They were exposed to a steady fast neutron flux of $1.5 \times 10^{10}$ $\mathrm{n} / \mathrm{cm}^{2}$-sec. The first irradiation cycle lasted for 44 minutes, and the $1^{\text {st }}$ set of ribbons were cut and allowed for decay to a suitable exposure level before they were shipped back to LLNL for post-irradiation examination (PIE). The second irradiation cycle lasted for 88 minutes, and the $2^{\text {nd }}$ set of ribbons with a cumulative radiation exposure of 132 minutes were cut. They were shipped back to LLNL for PIE after radioactive decay to a level suitable for shipment. The third irradiation cycle lasted for 131 minutes, and the last set of ribbons were shipped back to LLNL for PIE after allowance for radioactive decay. 
Table 6 shows the irradiation cycles and time of exposure in reactor for the 3 irradiation experiment. It also includes the calculation of total exposure fluence, defined as the flux multiplied by time, as well as the equivalent time, in years of radiation exposure of material inside the spent fuel containers in the Yucca Mountain repository environment.

X-ray diffraction is used to examine the melt-spun ribbons after the 3 series of irradiation experiment. The use of XRD is to identify the presence of crystalline phases in these ribbons. The XRD spectra of an amorphous material does not have sharp peaks; whereas, the XRD spectra of a crystalline material or a material that is a mixture of amorphous and crystalline material will have sharp peaks. The presence of crystalline phases in samples that have been heat treated at the use temperatures in the waste package would indicate an unacceptable coating.

Table 6 Irradiation Time, Fluence, and Equivalent Time in YM Environment for The 3 Irradiation Experiment

\begin{tabular}{llll}
$\begin{array}{l}\text { Irradiation } \\
\text { (fast flux }=1.5 \mathrm{e}^{10}\left(\mathrm{n} / \mathrm{cm}^{2} \text {-sec) }\right.\end{array}$ & $1 \mathrm{st}$ & 2nd & 3rd \\
\hline $\begin{array}{l}\text { Total Time Exposure in Reactor, } \\
\text { min }\end{array}$ & 44 & 132 & 263 \\
$\begin{array}{l}\text { Total Exposure Fluence, } \\
\text { flux x time }\end{array}$ & $4.0 \mathrm{e}^{13}$ & $1.2 \mathrm{e}^{14}$ & $2.4 \mathrm{e}^{14}$ \\
$\begin{array}{l}\text { Equivalent years in YM } \\
\text { Environment }\end{array}$ & 670 & 2010 & 4030 \\
\hline
\end{tabular}

\section{Irradiation Examination Results}

This section contains $\mathrm{x}$-ray diffraction (XRD) spectra for the four series of meltspun ribbons before and after the irradiation experiment. Figure 11 shows the pre- and post- irradiation XRD for SAM1X series. Figure 12 shows the preirradiation XDR for SAM2X and the DAR series. Figure 13 shows the postirradiation XRD of the SAM2X series. Figure 14 shows the post-irradiation XRD for the DAR series. It indicates that the DAR7 ribbon appears to show some kind of crystallinity after the $3^{\text {rd }}$ irradiation cycle. It is still unsure, however whether the crystalline tendency is due to the cumulative radiation effect or because of the brittleness of the small DAR7 sample which could affect the XRD measurement. Figure 15 shows the pre- and post- irradiation XRD for the SAM3X series. The results shown in Figures 11 to 15 indicate that apart from DAR7, extensive neutron irradiation does not change the structure of the amorphous melt-spun ribbons. 
Figure 11 Neutron Irradiation of SAM Ribbons (XRD of SAM1X Series)

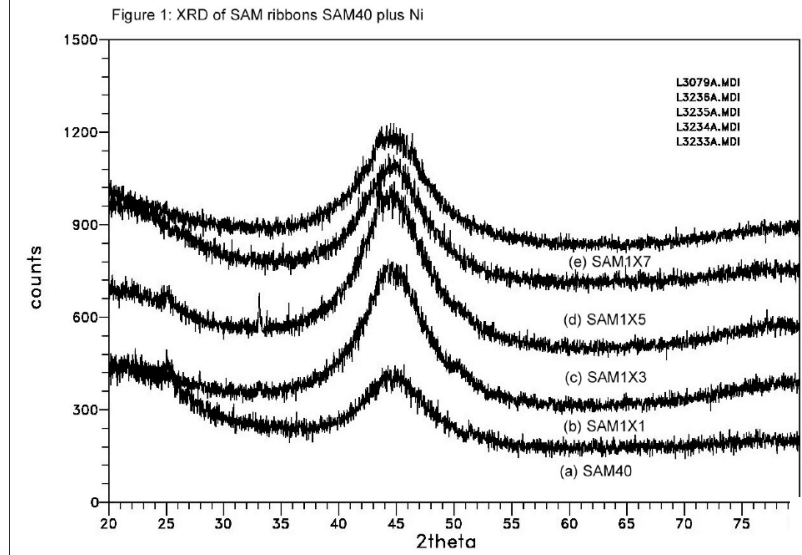

Pre-Irradiation XRD
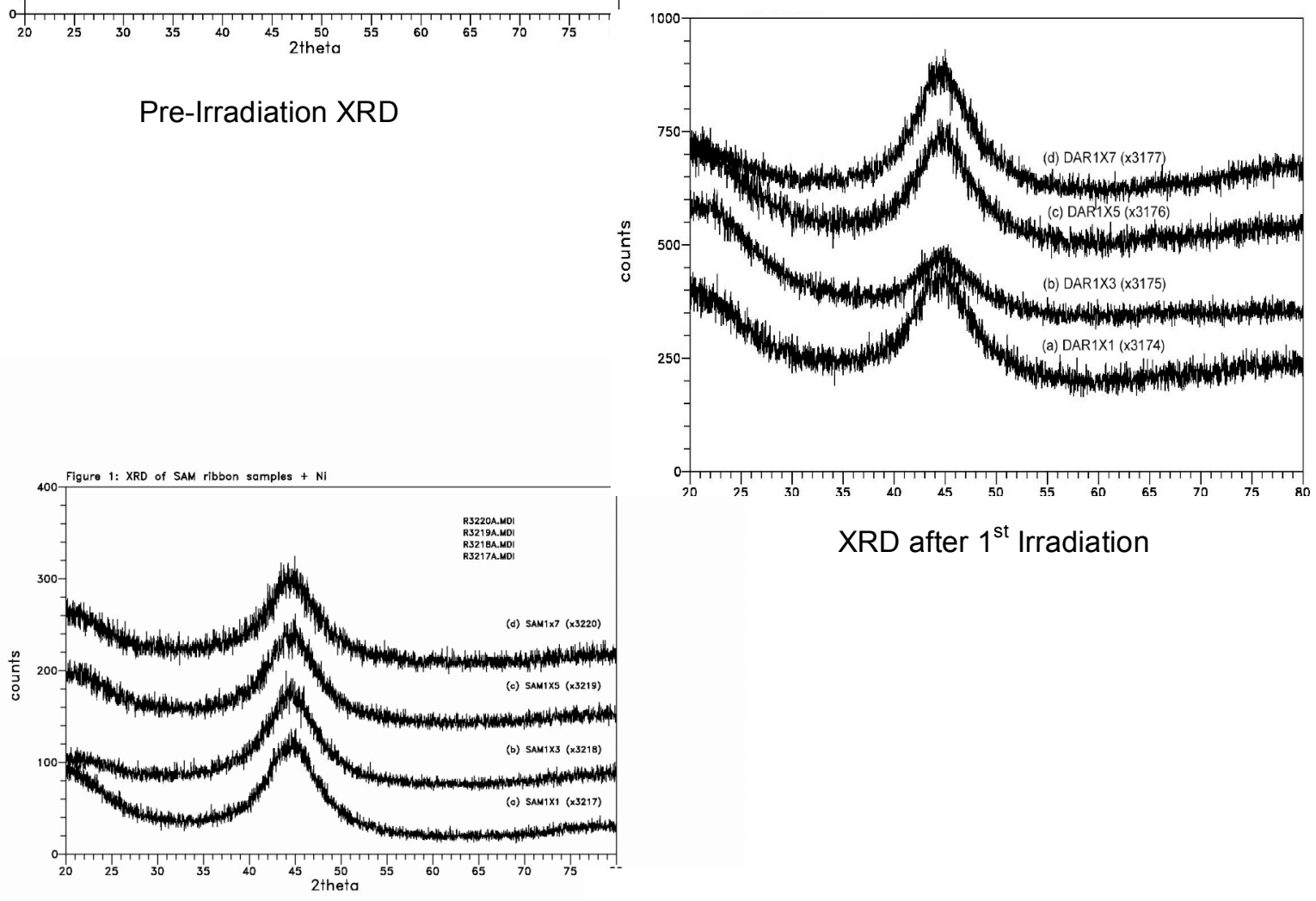

XRD after $2^{\text {nd }}$ Irradiation

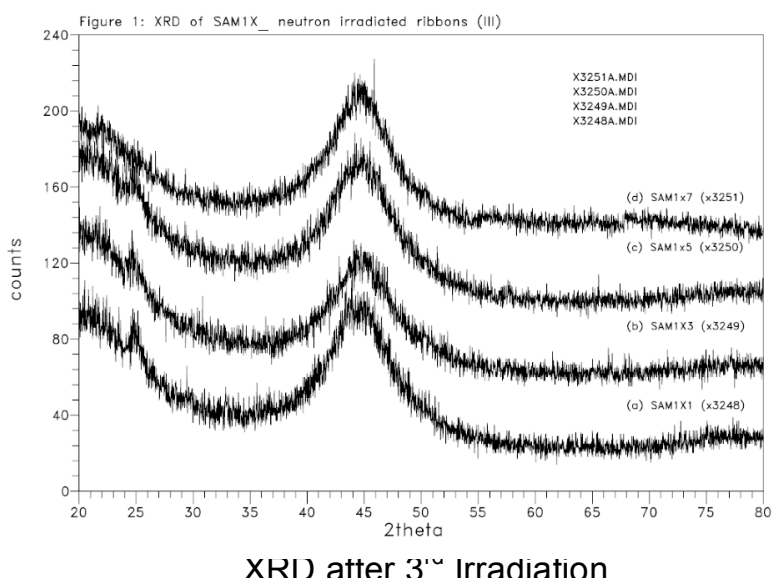


Figure 12 Neutron Irradiation of SAM Ribbons (XRD of SAM2X and DAR Series)

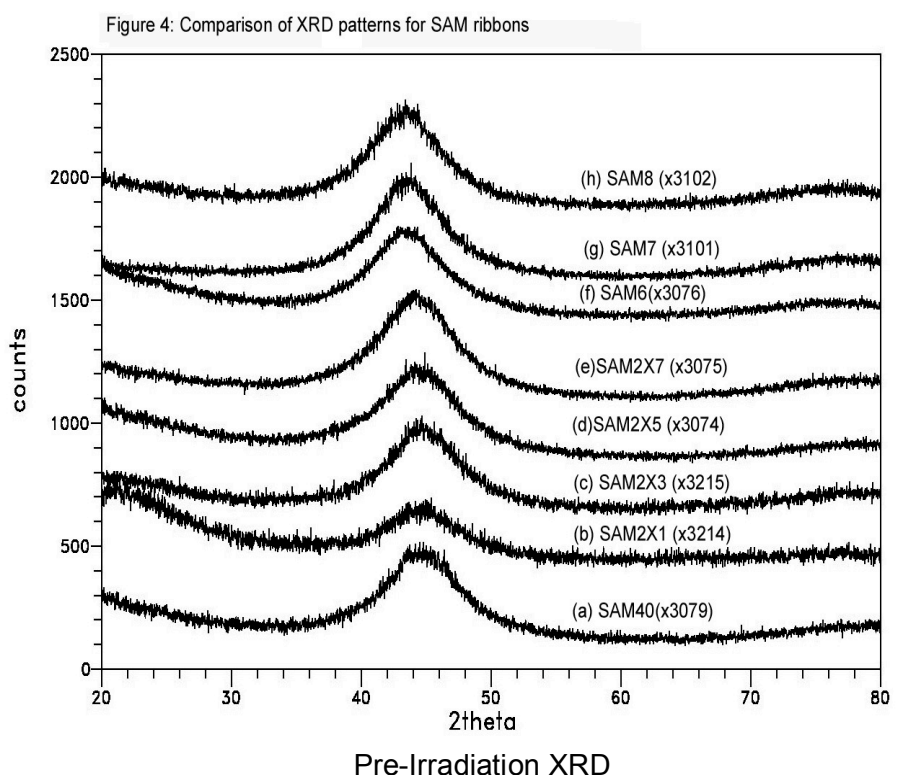

Figure 13 Neutron Irradiation of SAM Ribbons (XRD of SAM2X Series)

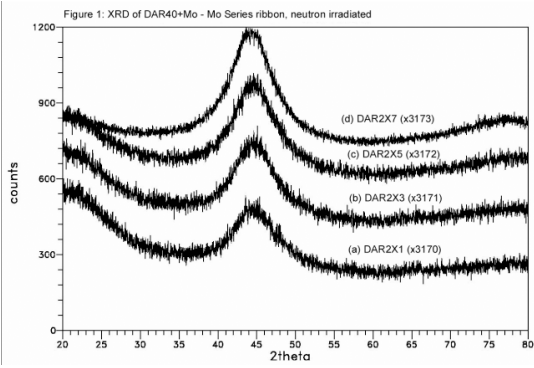

XRD after $1^{\text {st }}$ Irradiation
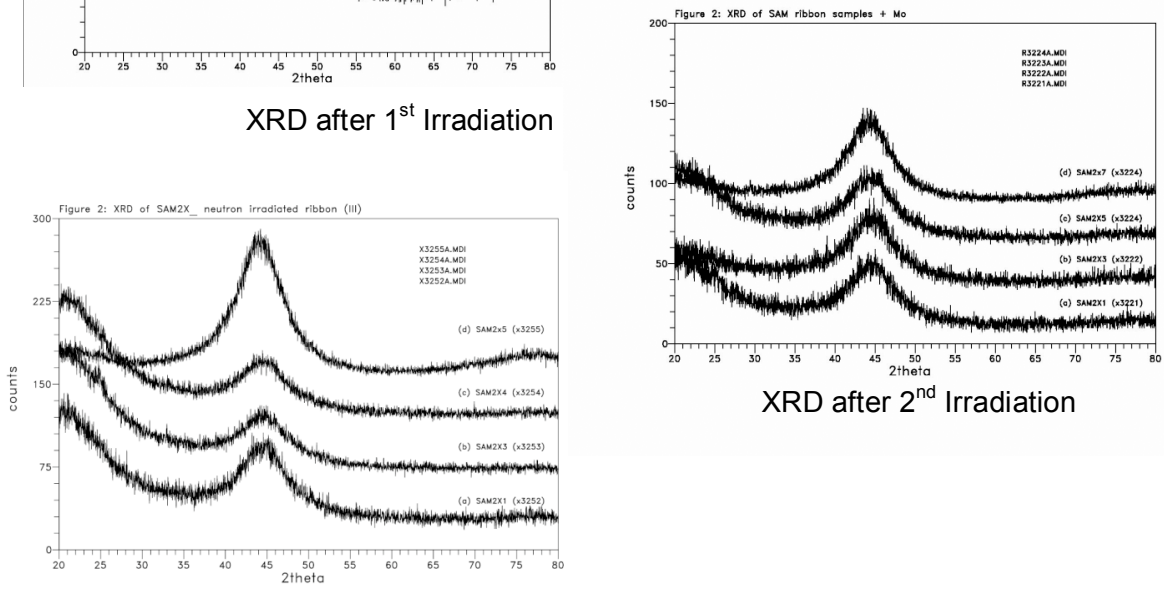

XRD after $3^{\text {rd }}$ Irradiation 
Figure 14 Neutron Irradiation of SAM Ribbons (XRD of DAR Series)
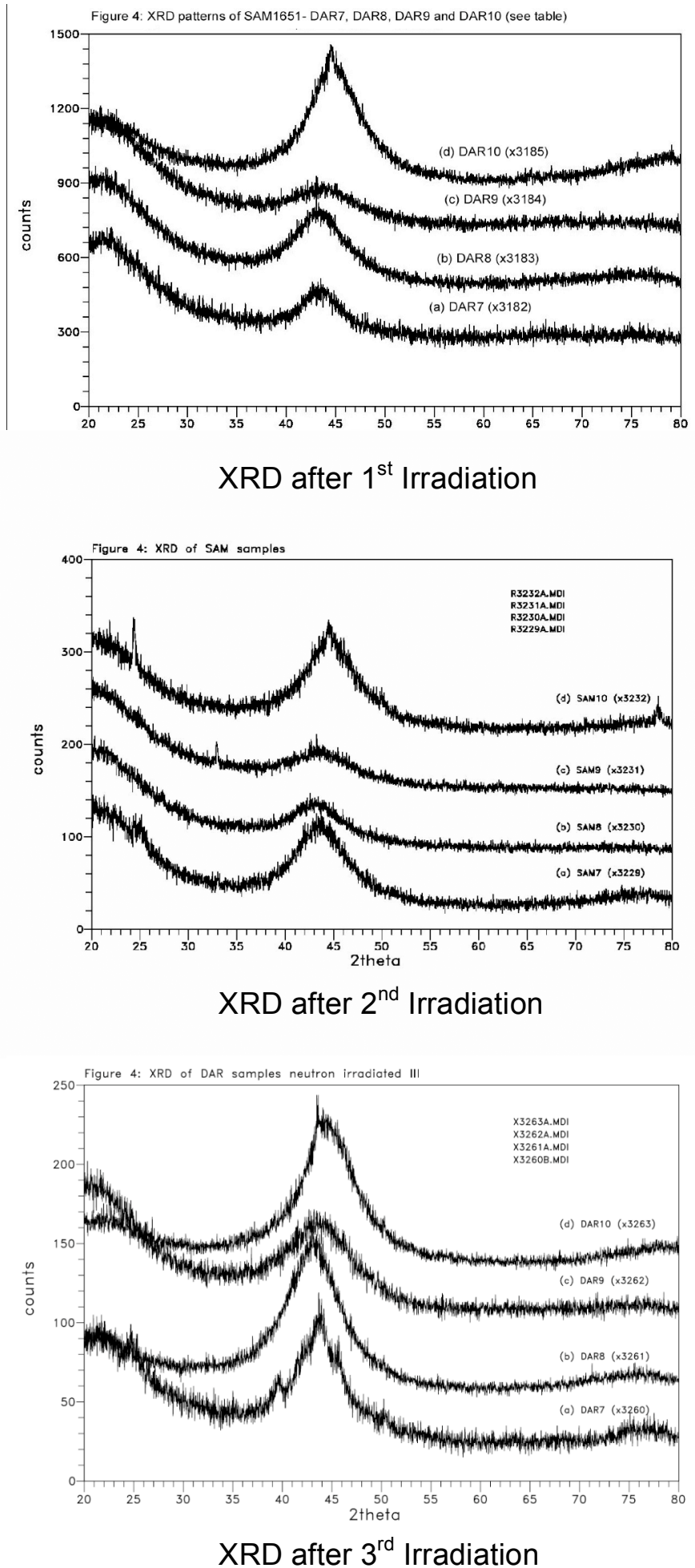
Figure 15 Neutron Irradiation of SAM Ribbons (XRD of SAM3X Series)

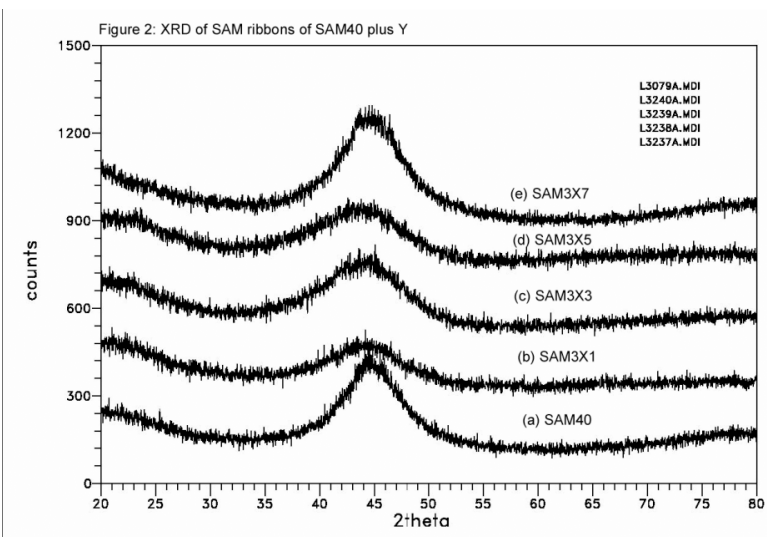

Pre-Irradiation XRD
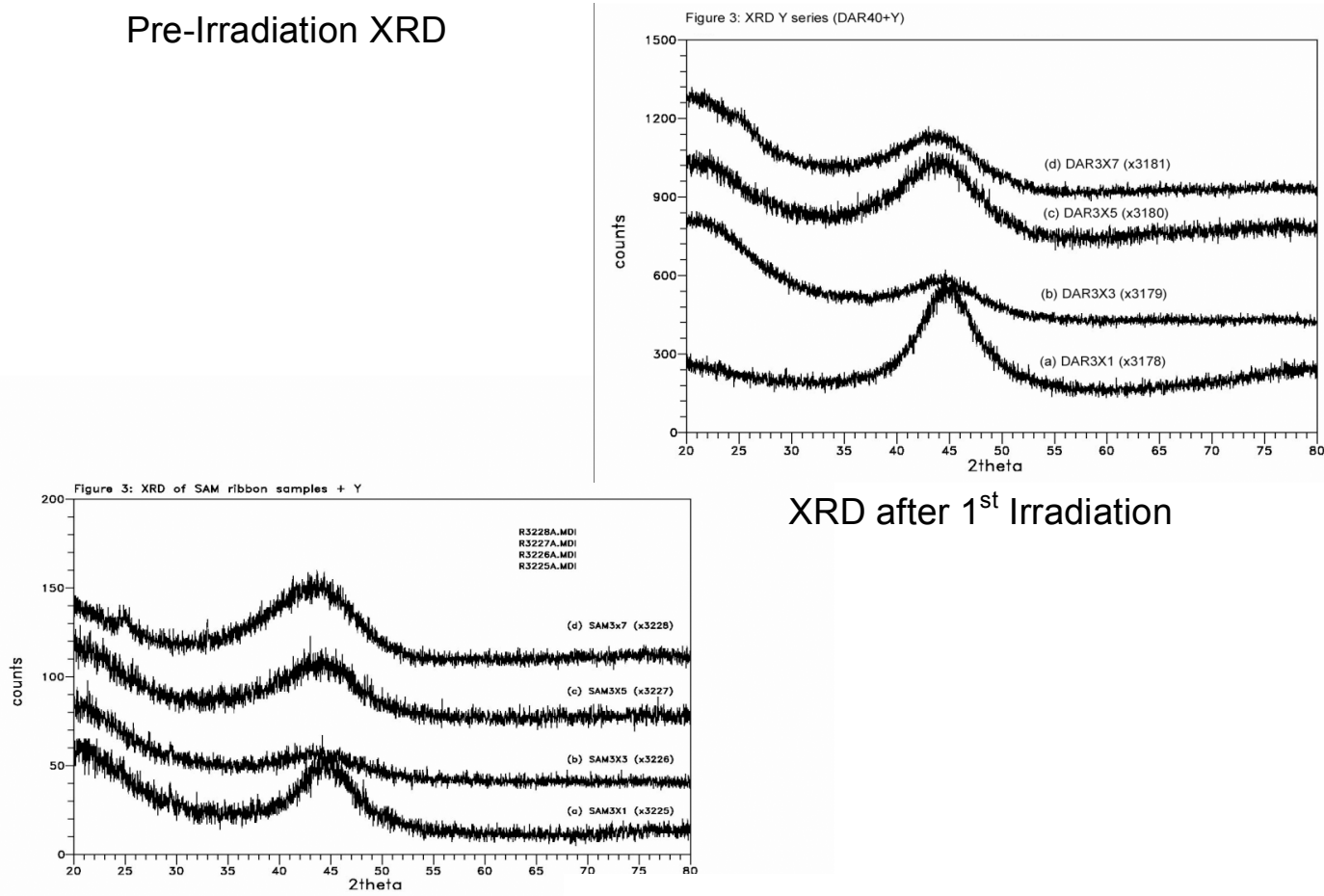

XRD after $2^{\text {nd }}$ Irradiation

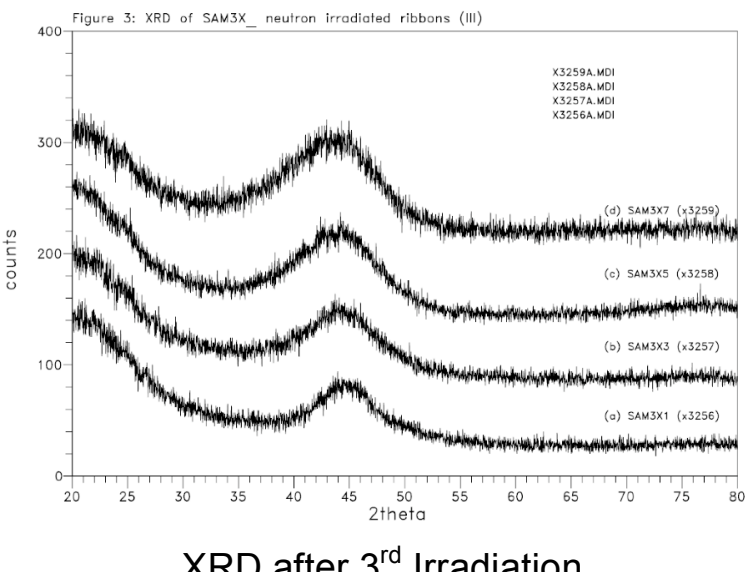




\section{$\underline{\text { Thermal Neutron Transmission }}$}

When thermal neutron passes through an absorbing material, it can be either absorbed, scattered away, or transmitted through. The ability of the neutron absorbing material to capture the neutron can be estimated by the transmission measurement. For strong thermal neutron absorbers (e.g., ${ }^{157} \mathrm{Gd},{ }^{155} \mathrm{Gd}$, and ${ }^{10} \mathrm{~B}$, etc) the thermal neutron incident intensity is reduced mainly by the absorption of neutron, and minimally by the scattering effect. The transmission intensity is hence, estimated based on the following relationship:

$$
\begin{aligned}
\mathrm{I}_{\mathrm{t}} & =\mathrm{I}_{0}{ }^{*} \mathrm{e}^{\left(-\sigma \mathrm{t}^{*} \mathrm{n}^{*} \mathrm{x}\right)} \\
& =\mathrm{I}_{0}{ }^{*} \mathrm{e}^{\left(-\mathrm{t}^{*} \mathrm{x}\right)}
\end{aligned}
$$

where $I_{t}$ is the thermal neutron transmission intensity

$\mathrm{I}_{\mathrm{o}}$ is the incident intensity of the thermal neutron

$\sigma$ is the microscopic transmission cross section

$\mathrm{n}$ is the atom density of the neutron absorbing material (e.g., ${ }^{10} \mathrm{~B}$, etc.) $x$ is the thickness of the neutron absorbing material

$\square_{t}$ is the macroscopic cross section, defined as the probability per unit path length that a neutron will interact as it moves about in a medium

The mean free path, $\lambda$ is defined as $1 / \square_{t}$, which is the average distance that a neutron moves between collisions.

Both the transmission and incident thermal neutron intensity can be measured by experiment. These transmission measurements were performed for various neutron absorbers including BoralTM, MetamicTM, Ni-Gd, and stainless steel substrates coated with SAM2X5. Figure 16 shows the schematic of the transmission measurement apparatus.

Figure 16 Schematic of the Transmission Measurement Apparatus

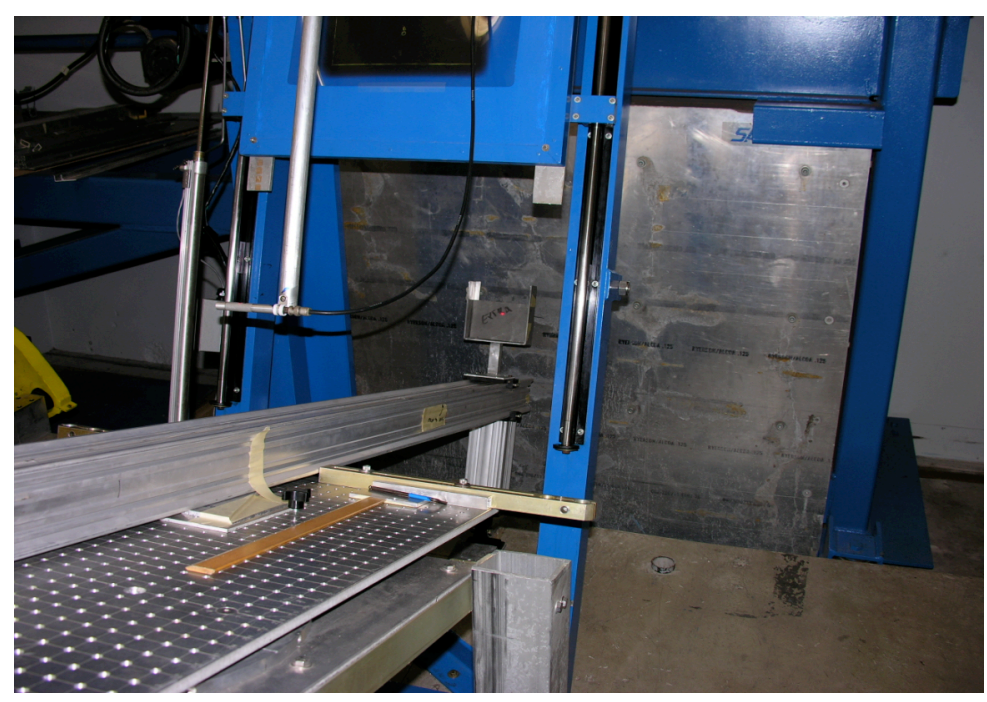




\section{Transmission Measurement Results}

Preliminary results of thermal neutron transmission measurements of various neutron absorbing materials are obtained. The results are shown in Table 7. It is noted that the SAM2X5 absorbs thermal neutron with an average neutron transmission cross section of about $7 \mathrm{~cm}^{-1}$. The average $\square_{\mathrm{t}}$ for the Ni-Gd plates is about 5.9 after adjusted for the "flux suppression" effect due to Gadolinium's huge absorption cross section. The results indicate the low $\square_{\mathrm{t}}$ for the borated stainless steel plates, due perhaps to the low boron content in these plates.

Table 7 Preliminary Results of Transmission Measurement of Various Neutron Absorbing Plates

\begin{tabular}{|c|c|c|c|c|c|c|}
\hline $\begin{array}{l}\text { Plate } \\
\quad \#\end{array}$ & Plate ID & Description & $\begin{array}{c}\text { Transmission } \\
\text { Count Rate } \\
\text { (cpm) }\end{array}$ & $\begin{array}{c}\text { Bare } \\
\text { Beam } \\
\text { Count } \\
\text { Rate } \\
\text { (cpm) }\end{array}$ & Ratio & $\begin{array}{c}\text { Transmission } \\
\text { Cross Section, } \\
\square_{\mathrm{t}}, \mathbf{c m}^{-1}\end{array}$ \\
\hline 1 & MNRC & $\begin{array}{l}\text { Boral } 40 \text { mil or } 0.1 \\
\mathrm{~cm} \text { thick }\end{array}$ & 7550 & 73017 & 0.103 & 22.7 \\
\hline $2^{*}$ & $316 \mathrm{~L}$ & $\begin{array}{l}\text { Base plate, } 1 / 4 " \text { or } \\
0.635 \mathrm{~cm} \text { thick }\end{array}$ & 39309 & 77478 & 0.507 & 1.07 \\
\hline $3^{*}$ & C22 & $\begin{array}{l}\text { Base plate, } 0.28 \text { " or } \\
0.711 \mathrm{~cm} \text { thick }\end{array}$ & 31033 & 77478 & 0.401 & 1.29 \\
\hline $4^{*}$ & M18W3 & $\begin{array}{l}\text { C22 1/8" or } 0.317 \mathrm{~cm} \\
\text { thick with coating }\end{array}$ & 26831 & 77478 & 0.346 & 6.52 \\
\hline 5 & M10S14 & $\begin{array}{l}\mathrm{C} 221 / 4 \text { " or } 0.635 \mathrm{~cm} \\
\text { thick with coating }\end{array}$ & 14482 & 70644 & 0.205 & 7.65 \\
\hline $6(1)^{\#}$ & $\mathrm{NiGd}$ & $\begin{array}{l}\text { Labeled "Extra", 3/8" } \\
\text { or } 0.952 \mathrm{~cm} \text { thick }\end{array}$ & 1948 & 70644 & 0.0276 & 3.77 \\
\hline $6(2)^{\#}$ & $\mathrm{NiGd}$ & $\begin{array}{l}\text { Labeled "Extra", 3/8" } \\
\text { or } 0.952 \mathrm{~cm} \text { thick }\end{array}$ & 1897 & 70095 & 0.0271 & 3.79 \\
\hline 7 & Metamic & $\begin{array}{l}\mathrm{B}_{4} \mathrm{C} / \mathrm{Al}, 1 / 16^{\prime \prime} \text { or } \\
0.158 \mathrm{~cm} \text { thick }\end{array}$ & 4891 & 70644 & 0.0692 & 16.9 \\
\hline $8^{\#}$ & $\mathrm{NiGd}$ & $\begin{array}{l}\text { Labeled (1), 3/8" or } \\
0.952 \mathrm{~cm} \text { thick }\end{array}$ & 1637 & 67700 & 0.0242 & 3.91 \\
\hline $9^{\#}$ & $\mathrm{NiGd}$ & $\begin{array}{l}\text { Labeled (2), 3/8" or } \\
0.952 \mathrm{~cm} \text { thick }\end{array}$ & 1672 & 67700 & 0.0247 & 3.89 \\
\hline 10 & 316L-C1 & $\begin{array}{l}316 \mathrm{~L} 1 / 4 " \text { or } 0.635 \\
\mathrm{~cm} \text { thick with coating }\end{array}$ & 26037 & 68622 & 0.379 & 5.82 \\
\hline 11 & 316L- C2 & $\begin{array}{l}316 \mathrm{~L} 1 / 4 " \text { or } 0.635 \\
\mathrm{~cm} \text { thick with coating }\end{array}$ & 24875 & 68622 & 0.362 & 6.73 \\
\hline 12 & 316L-W1 & $\begin{array}{l}316 \mathrm{~L} 1 / 4 " \text { or } 0.635 \\
\mathrm{~cm} \text { thick with coating }\end{array}$ & 24026 & 67928 & 0.354 & 7.18 \\
\hline 13 & 316L-W2 & $\begin{array}{l}316 \mathrm{~L} 1 / 4 " \text { or } 0.635 \\
\mathrm{~cm} \text { thick with coating }\end{array}$ & 24263 & 67928 & 0.357 & 7.01 \\
\hline 14 & C22- C15 & $\begin{array}{l}\text { C22 1/4" or } 0.635 \mathrm{~cm} \\
\text { thick with coating }\end{array}$ & 21555 & 67062 & 0.321 & 6.34 \\
\hline 15 & C22- C16 & $\begin{array}{l}\text { C22 1/4" or } 0.635 \mathrm{~cm} \\
\text { thick with coating }\end{array}$ & 19500 & 67062 & 0.291 & 8.30 \\
\hline 16 & C22- W15 & $\begin{array}{l}\text { C22 1/4" or } 0.635 \mathrm{~cm} \\
\text { thick with coating }\end{array}$ & 19876 & 68606 & 0.290 & 8.37 \\
\hline
\end{tabular}




\begin{tabular}{|c|l|l|c|c|c|c|}
\hline 17 & C22- W16 & $\begin{array}{l}\text { C22 1/4" or 0.635 cm } \\
\text { thick with coating }\end{array}$ & 20857 & 68606 & 0.304 & 7.43 \\
\hline $18^{\#}$ & 182193 & $\begin{array}{l}\text { Borated S.S. 5/8" or } \\
1.587 \mathrm{~cm} \text { thick }\end{array}$ & 4438 & 63011 & 0.0704 & 1.67 \\
\hline 19 & 182194 & $\begin{array}{l}\text { Borated S.S. 5/8" or } \\
1.587 \mathrm{~cm} \text { thick }\end{array}$ & 1904 & 63011 & 0.0302 & 2.21 \\
\hline 20 & 182196 & $\begin{array}{l}\text { Borated S.S. 5/8" or } \\
1.587 \mathrm{~cm} \text { thick }\end{array}$ & 1014 & 63011 & 0.0161 & 2.60 \\
\hline 21 & 03180 & $\begin{array}{l}\text { Borated S.S. 5/8" or } \\
1.587 \mathrm{~cm} \text { thick }\end{array}$ & 941 & 63011 & 0.0149 & 2.65 \\
\hline
\end{tabular}

Runs at $1.8 \mathrm{MW}$ operating power.

** Note: Differences of bare beam count rates are due to the adjusted location of $\mathrm{BF}_{3}$ chamber at the time of experiments and the specific time of experiments and the specific conditions of the reactor operation.

\# Due to "flux suppression" for Gadolinium's huge absorption cross section the calculated transmitted ratio is 0.00405 compared to measured $0.0276,0.0271,0.0242,0.0247$, resulting in a factor of $>6$, the macroscopic cross section, sigma becomes 5.78 instead of measured $3.77,3.79,3.91,3.89$.

\#\# $\quad \mathrm{BF}_{3}$ chamber is moved $>5$ ' away from the sample plates. Note: little difference in ratio compared to $\mathrm{BF}_{3}$ chamber located at $>4$ ' away.

\section{Neutron Radiography Facility}

MNRC is specialized in neutron radiography and tomography. It consists of 4 radiography bays accommodating various large sizes of radiation parts and specimen. It is the only facility in the world capable of effectively performing nondestructive neutron imaging of large titanium castings. Figures 17 and 18 show the configuration of the bays and the schematic of the neutron radiography arrangement, respectively.

\section{Figure 17 Configuration of the Neutron Radiography Bays in MNRC}

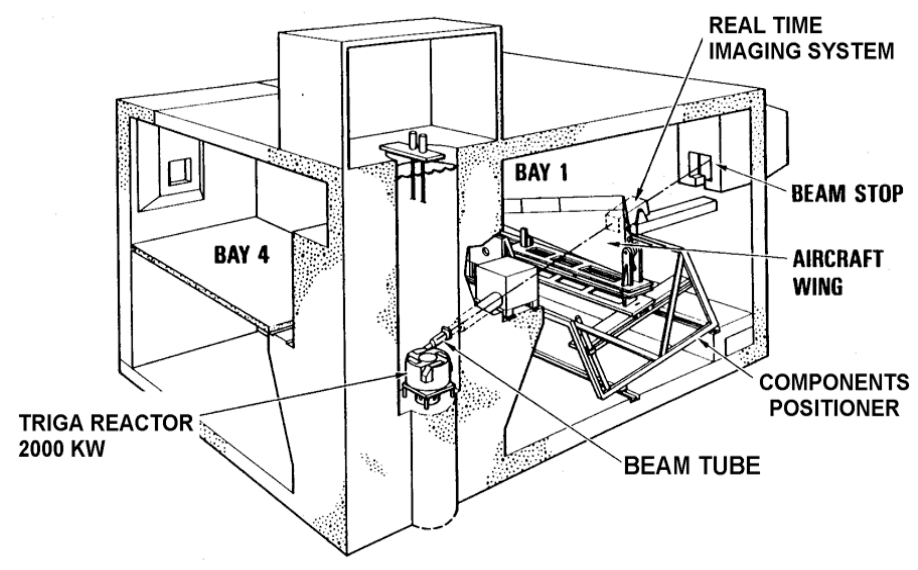


Figure 18 Schematic of the Neutron Radiography Arrangement

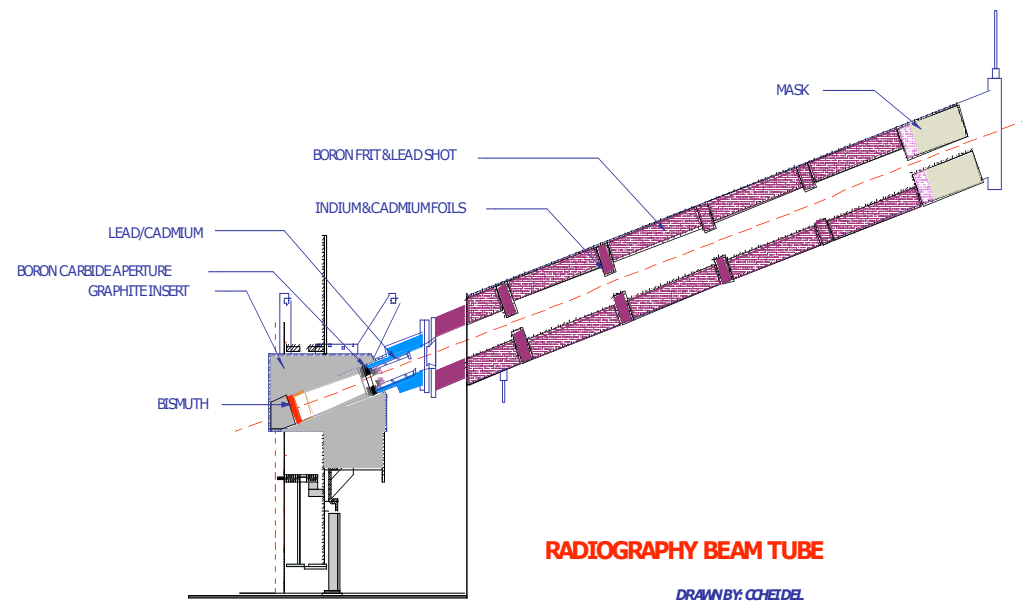

The neutron radiograph on 3 nickel-based alloy C-22 plates (4" x 4" x 1/4") and a large (12" x 12" x 1") plate coated with SM2X5 amorphous-metal coating were taken. Figure 19 shows the images of the $3 \mathrm{C}-22$ plates and the large plate.

Figure 19 Neutron Radiograph of C-22 Plates Coated with SAM2X5

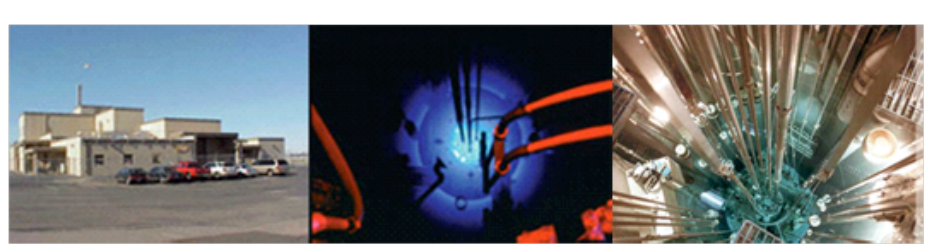

Neutron Radiography at University of California's 1.5 MW TRIGA Nuclear Reactor

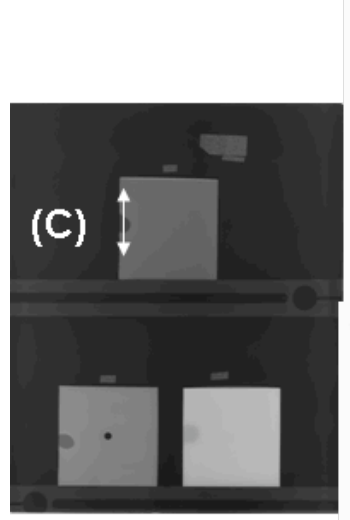

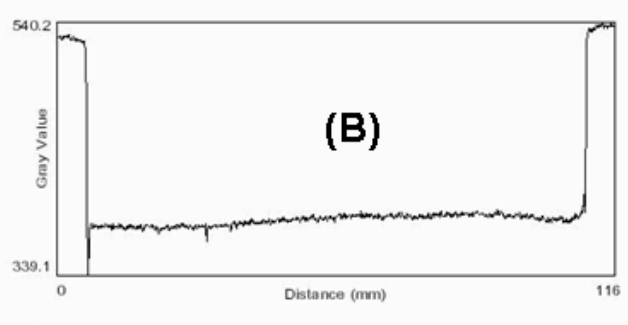

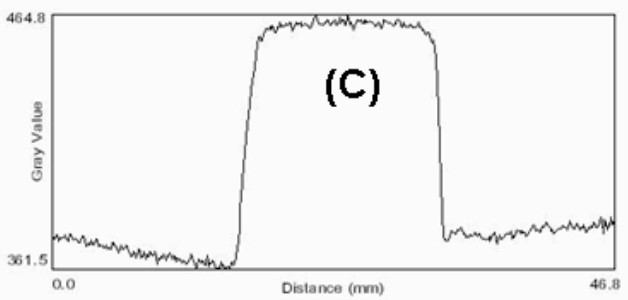

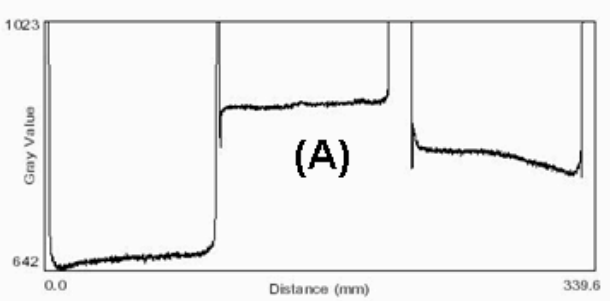

(A)

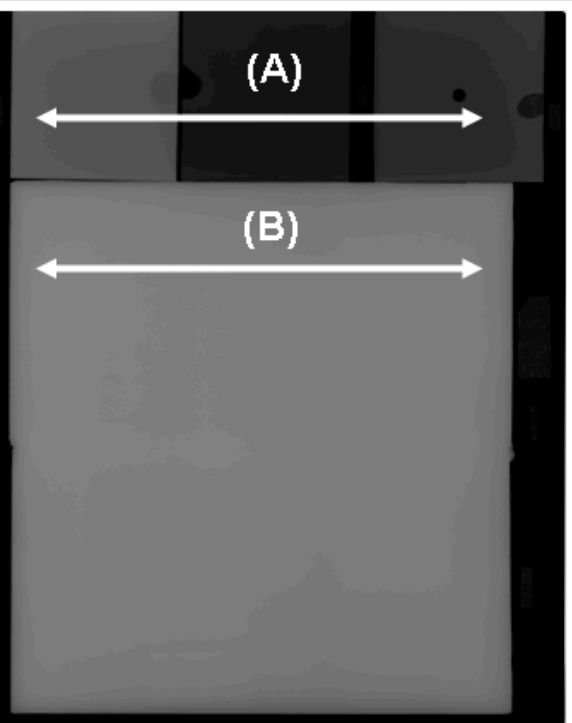




\section{QUALIFICATION PLAN FOR HPCRM}

\section{Qualification of SAM as Neutron-Absorbing Materials}

For criticality control of nuclear fuel in storage and transportation, the most commonly used neutron absorber materials are borated stainless steel alloy, boron-aluminum alloys and boron carbide-aluminum alloy composites. The boron used in these neutron absorber materials may be natural or enriched in the nuclide ${ }^{10} \mathrm{~B}$. The boron is usually incorporated either as an inter-metallic phases (e.g., $\mathrm{AlB}_{2}, \mathrm{TiB}_{2}, \mathrm{CrB}_{2}$, etc.) in an aluminum alloy or stainless steel, or as a stable chemical compound particulate such as boron carbide $\left(\mathrm{B}_{4} \mathrm{C}\right)$, typically in an aluminum metal matrix composite or cermets.

The boron in the SAM coating should behave like a stable metal matrix composite homogeneously distributed within the amorphous metal. When SAM coating is applied and placed within the spent fuel container, it would be inaccessible and not amenable to a surveillance program. When the spent fuel is emplaced in the geologic repository, the SAM coating is expected to perform over an extended time period.

This would challenge the qualification and acceptance procedures which would be use to demonstrate that the SAM coating has the necessary characteristic to perform its design functions during its long service lifetime. The SAM coating would be exposed to neutron and gamma radiation during its service lifetime, this potentially could degrade its neutron-absorbing effectiveness.

To evaluate the neutron attenuation capability of the amorphous metal coating and to simulate the radiate environment which the amorphous metal coating would expose to, neutron radiation testing is planned as part of the qualification and acceptance program for SAM2X5 and SAM1651.

\section{Qualification of SAM under ASTM Standard Subcommittee C26.03}

The qualification of the boron-containing amorphous metal under the Standard Subcommittee $\mathrm{C} 26.03$ would consists of first the determination of service conditions and design requirements which the amorphous metal coatings or bulk materials will be exposed to. The goal is to verify the durability of the amorphous metal materials for the intended service conditions and to verify that the physical characteristics of amorphous metal materials meet their design requirements.

For neutron absorber qualification, we will perform neutron attenuation testing at MNRC to verify the absorber's effectiveness, and to verify by radiation, thermal, and corrosion testing that the amorphous metal coating does not undergo physical changes that would render it unable to perform its design functions. 
For neutron absorber acceptance, we will identify key processes and controls in manufacturing the amorphous metal materials and to establish an acceptance testing program (statistical sampling plan, test locations, etc.) for neutron absorber content and uniformity which would conform to the standard practice for qualification and acceptance of boron-based metallic neutron absorbers for nuclear criticality control.

\section{CONCLUSIONS}

- The study concludes that the high boron-containing SAM2X5 coating can be an effective criticality control material for the spent fuel containers. Criticality analysis performed in this study indicate that a $1 \mathrm{~mm}$ SAM2X5 coating applied on the surfaces of the spent fuel basket could reduce the $\mathrm{k}_{\text {eff }}$ by almost $10 \%$, equivalent to about $1 \mathrm{wt} \%$ boron-loading in $1 / 4$ ' thick borated stainless steel.

- The HVOF thermal-spray process is a demonstrated technology to apply coating onto alloy substrates. This process was used by Plasma Technology, Inc. to thermal-spray SAM2X5 powder onto the spent fuel basket modules made out of stainless steel $316 \mathrm{~L}$. Analysis on microstructure, hardness and bond-strength indicated that the coating meets the industrial standard.

- The neutron irradiation experiment performed on the melt-spun ribbons indicated that apart from DAR7 which exhibited a slight tendency for crystallinity after exposing to a fast neutron fluence of $6.7 \mathrm{e} 17 \mathrm{n} / \mathrm{cm}^{2}$, extensive neutron irradiation does not change the structure of the amorphous melt-spun ribbons.

- The neutron transmission measurements indicate that SAM2X5 exhibit effective neutron absorbing capability, similar to other boron-based neutron absorbers such as Boral $^{\mathrm{TM}}$, and Metamic ${ }^{\mathrm{TM}}$.

- It is important to establish an effective qualification and acceptance plan for qualifying SAM2X5 as a neutron-absorbing material for the transportation, aging, and disposal containers in the next phase of the HPCRM Program R\&D. 


\section{References}

1. J. C. Farmer, J. J. Haslam, S. D. Day, D. J. Branagan, M. C. Marshall, B. E. Mecham, E. J. Buffa, C. A. Blue, J. D. K. Rivard, D. C. Harper, M. B. Beardsley, D. T. Weaver, L. F. Aprigliano, L. Kohler, R. Bayles, E. J. Lemieux, T. M. Wolejsza, N. Yang, G. Lucadamo, J. H. Perepezko, K. Hildal, L. Kaufman, A. H. Heuere, F. Ernst, G. M. Michal, H. Kahn, E. J. Lavernia, HighPerformance Corrosion-Resistant Materials: Iron-Based Amorphous-Metal Thermal-Spray Coatings, High-Performance Corrosion-Resistant Materials (HPCRM) Annual Report, UCRL-TR-206717, Lawrence Livermore National Laboratory, Livermore, California, 178 pages, September 28 (2004).

2. 12. MCNP, developed by the Los Alamos National Laboratory, is a general Monte Carlo N-Particle code. 